\section{The dynamics of external provision in physical education}

\author{
Jessica Mangione
}

Edge Hill University, UK

\section{Melissa Parker}

University of Limerick, Ireland

\section{Mary O'Sullivan}

University of Limerick, Ireland
European Physical Education Review $1-18$

(C) The Author(s) 2021

\section{(c) (i)}

Article reuse guidelines: sagepub.com/journals-permissions DOI: | 0.1 | 77//|356336X21 106596| journals.sagepub.com/home/epe

@SAGE

\begin{abstract}
Neoliberalism is a pervasive phenomenon. A fundamental neoliberal concept allows for the selection of the best and most suitable option available for a specific course of action in any aspect of society. Not unexpectedly, the educational field, including physical education (PE), has been influenced by neoliberal ideas. A key element of neoliberalism in PE is the selection of workers external to the school system, as a suitable option to improve the educational experience. The involvement of external workers increases the diversity of stakeholders in the school system, who, with their actions and decisions, have the potential to influence the content and status of PE in schools. The purpose of this study was to understand the external provision infrastructure supporting PE in an Irish primary school. Specifically, we used network ethnography to understand the structure and the impact of external provision on school PE. Participants included two primary school teachers, the school PE coordinator and one PE external provider. Data analysis resulted in two themes. The first theme refers to the structure of the external provider system, and the second to the dynamics of the network between the main stakeholders. Taken together, a well-established external provision network in the school is revealed but the structure of the network, as designed, is not supporting PE as intended by the Irish educational system.
\end{abstract}

\title{
Keywords
}

Outsourcing, network ethnography, network analysis, neoliberalism

\section{Corresponding author:}

Jessica Mangione, Department of Sport and Physical Activity, Edge Hill University, Ormskirk, UK. Email: mangionj@edgehill.ac.uk 


\section{Introduction}

Neoliberalism was originally associated with economic and market systems. Larner (2003), however, described neoliberalism as a phenomenon influencing everything and everywhere. Ball et al. (2017) argued that neoliberalism adapts to the local culture and political landscape, adopting features that sometimes are typical of a specific country or event. Macdonald (2014: 495) suggested that:

Neo-liberalism can be understood as a complex and contradictory set of practices and discourses organised around market-based social relationships, commodification, capital accumulation, profit-making, retreat of government services through outsourcing and privatisation, and individualisation of responsibility through the capacity to make (sound) choices.

This makes it clear that as part of neoliberal ideology, the freedom of making the best decision is extended to all aspects of life including health, lifestyle, work and education (Macdonald, 2011). In the same way as an individual can make the 'best choices', school administrations (or managers, etc.) have the freedom to make decisions they believe can lead to improving the quality of their students' education (Macdonald, 2011, 2014). This concept of freedom has been problematised by several scholars (Evans and Davies, 2014, 2015; Macdonald, 2011), suggesting that despite individuals and schools having the freedom to make their own choices, these can be limited freedoms due to other conditions and do not always allow for good choices.

In an attempt to recognise differences related to 'consumer' tastes and needs (in this case children in school), neoliberalism in education promotes choosing the best curricular options even if that means using a variety of personnel to provide these options. It is relevant to note that there are other reasons external providers enter schools, such as perceived lack of expertise by teachers in some areas (Petrie et al., 2014) and/or perceived beliefs that external providers can deliver this experience more effectively and/or efficiently as in the perspective that the educational experience can be served by those with expertise external to the education profession (Williams and Macdonald, 2015). Therefore, educational opportunities offered are designed for a given population. This freedom by educational leaders to make, what they believe to be, the best educational decisions for particular student populations, has resulted in the involvement of workers in schools who are external to the school system (Ball, 2004). In other words, schools hire external contract staff to provide programmatic choice with the aim to increase educational offerings and/ or improve the quality of curriculum.

While there are a variety of reasons and interpretations of the external provision phenomenon, scholars (Evans and Davies, 2015; Macdonald, 2014; Powell, 2015) who have studied the process from different perspectives frequently link the outsourcing process with neoliberalism. The use of external people (coaches, athletes and volunteers) in the enactment of physical education (PE), also known as outsourcing, is an increasingly common practice worldwide (Bowles and O'Sullivan, 2012; Dyson et al., 2016; Parnell et al., 2016a, 2016b; Sperka and Enright, 2017a, 2017b). Outsourcing in PE is defined as the process of curriculum work (both instruction and planning) sourced from outside the organisational resources of the school being enacted inside the school by an external entity (Lair, 2012; Sperka and Enright, 2017a, 2017b; Williams and Macdonald, 2015). These services include the enactment of PE programming and/or physical activity (PA) ${ }^{1}$ experiences. Macdonald (2014) suggests the external provision process as the main effect of neoliberalism in the field of PE. 
In Ireland, there is a long history of people external to the school delivering PE provision in the school setting, but little research exists on their impact on the quality of the educational experiences provided to children. Yet, the presence of external providers in the school system has the potential to influence the content and status of PE in the school setting. In the Irish context, this external provision is a largely unregulated system with most people working with children in these situations having no formal educational qualifications. The Department of Education and Skills (2018) and the Irish Primary Physical Education Association (2010) have both issued guidelines as to who and how external providers should be invited to engage with students on elements of the school curriculum; however, adherence to these recommendations is variable. At present, the sole qualification to work with young people is police vetting (Bowles and O'Sullivan, 2012; Ní Chróinín, 2017), a legal requirement for all those working with children or vulnerable people in any setting. Furthermore, these people come from different backgrounds (education, careers, sporting experiences), reflecting a broad variety of experiences with and expectations for children's engagement in PA. Their involvement in an already complex education system creates further issues arising from their diverse characteristics. Therefore, the purpose of this study was to understand the external provision infrastructure supporting PE in an Irish primary school. The research questions that guide this paper are: 'How does the external provision infrastructure supporting PE work in an Irish primary school?' and 'What were the key features and impact of external provision on school PE?'

\section{Theoretical framework: From infrastructure to network?}

The concept of a network has been used as a relevant framework to analyse the complexity of contemporary society. Hence, any social organisation can be understood and analysed as a network (Nohria, 1992). According to Sayama et al. (2016), a network can refer to a group of people, to technical infrastructure such as a communication system and the internet. Due to the complexity of the concept and its multiple uses, several definitions have been developed in relation to the field of use.

In the educational field, scholars define networks in a variety of ways. Hadfield et al. (2006: 5) noted networks are, 'groups or systems of interconnected people and organizations (including schools) whose aims and purposes include the improvement of learning and aspects of well-being known to affect learning'. de Lima (2010: 4) suggested that a network refers to 'a set of actors and the direct and indirect ties that exist among them'. Alternatively, Ball et al. (2017) defined networks as a complex set of connections between people, objects and technologies that are always under construction and reconstruction. These definitions coalesce around the relationships between the elements of the network. Ball's definition of network was the one used as a lens conducting this study. de Lima's (2010) work on how to study networks was used in this project. He found that in order to study networks in education, a more analytical and systematic description of the networks was needed. He identified key dimensions for the analysis of networks: (1) genesis, (2) composition, (3) structure, (4) substance and (5) effectiveness and dynamics of a network. The five dimensions of a network by de Lima have been used to identify and analyse the elements of the PE network in this study.

The genesis dimension refers to the network initiator, and as a consequence, the owner of the network. Understanding the network ownership aids in the recognition of reasons stakeholders agree to join the network (Barringer and Harrison, 2000). The actors of the network are classified within the composition dimension. Network actors may be individuals and/or groups of people. 
When the network is composed of individuals, it is identified as an 'individual-actor network'; in contrast, when people are grouped together, such as in organisations or institutions, these are referred to as 'collective actor networks'. In addition, de Lima introduced two more complex network types. In 'mixed-level networks', the actors are both individuals and groups simultaneously, while in 'meta-networks', the actors are networks of networks. In this last case, the actors of the network are already networks; it is these 'meta-networks' that are the most complex.

The third dimension, structure, refers to possible relationships between the actors. These connections can be analysed from two perspectives: 'whole system structure' and 'individual member structures'. Whole system structure relates to the characteristics of the relationships within the complete network. The second perspective is that of an individual member in the network; in other words, structural issues regarding the single actor, rather than issues relevant to the whole network. de Lima (2010) suggested that aspects of the structural dimension such as density, centralisation and connectedness could be particularly relevant to the study of networks in education. They might help in understanding the relationships between all the actors and the integration of the network as a social system, the distribution of the power around the network and the cohesion of the network.

The substance dimension of a network reflects the purpose(s) of the actors who interact within the network. de Lima (2010) noted studies that analyse this network dimension should include three different tasks: understanding the number and nature of areas in which the network is operating, how the network works and the nature of the agreement between the actors of the network. Lastly, the effectiveness dimension seeks to determine if the network is working or not and the effect it will have on the educational setting. de Lima (2010: 9) recognised this as the most difficult of the network dimensions to study due to the dynamism of the relationships involved. He affirmed that 'a network can often operate in an uncoordinated and incoherent fashion and its activity may be weakly related to the core of classroom life'. In order to understand this dimension more completely, in the last decade several scholars have proposed different strategies and frameworks to delineate the effectiveness of a network. Particularly relevant, in relation to the purpose of this study, is the framework elaborated by the ET2020 Working Group of the European Commission, which will help us to study the effectiveness dimension of our network. The ET2020 Working Group Schools developed a three-step cycle to explain how education networks should optimally function in order to be effective. The elements of the cycle are process, goals and structure.

The Commission explained that the goal(s) should be the starting point of the network, and the process and structure elements should be generated from this point. The development of this cyclical model stresses the idea of a network as a dynamic structure always in motion and in evolution, in support of a shared goal. In other words, the shared goals should be considered as the nucleus of the construction and deconstruction process described by Ball et al. (2017). On the other hand, the lack of effectiveness of any network (what de Lima terms the dark side of the network) occurs when one or more of the following occurs among stakeholders: power imbalance, loss of autonomy, financial risks, management complexities, loss of proprietary information, loss or organisational flexibility and a clash between cultures (de Lima, 2010). For the goal of this paper the first three are taken into consideration (power imbalance, loss of autonomy and financial risks). Power imbalance is particularly common in a network where an expert is involved as, usually, other actors will rely more on this person due to their expertise. Loss of autonomy refers to the lack of independence experienced by actors in decision making. In other words, more actors involved in the decision-making process reduces the independence 
of any of them. Finally, financial risk supports the idea that some actors involved in the network may see it as a tool for their own financial income without considering the benefits to the full network.

\section{Method}

\section{Network ethnography}

Ball et al. (2017) suggested that because a network involves interactions among a cohort of individuals it is important to understand both the structure of the network and the perspectives of the actors involved. Due to the complexity of outsourcing as a phenomenon, the method used to carry out the study was network ethnography. According to Howard (2002), network ethnography is a research method combining techniques typical of both ethnography and social network analysis (Ball, 2012; Howard, 2002). This method uses interviews and observations distinctive of traditional ethnography, and graphical representation typical of social network analysis (the results of the graphical analysis are reported in Mangione et al., 2020). This method was chosen because the use of network ethnography in educational research allows for the study of the social organisation of pedagogic spaces from a variety of dimensions. In this instance, the influence of the marketisation effect of neoliberalism in the school system, the interests of different stakeholders and the status of PE in primary schools create a complex scenario of interrelated dimensions suitable for the use of network ethnography.

\section{School selection}

This study is part of a larger research project focused on mapping external provision in support of PE in Irish primary schools. A list of 67 designated 'Delivering Equality of Opportunity in Schools' $(\mathrm{DEIS})^{2}$ schools involved with external providers for PE/PA were the focus of the larger project. The previous study, a network analysis, focused on understanding the most common forms of external provision within the identified cohort of schools while identifying the schools with the greatest amount of PE/PA external provision (Mangione et al., 2020). We contacted three schools with the greatest amount of external provision, but at the time of data collection, only one school was engaging with the external providers and they agreed to be involved in this study. In other words, the network analysis aspect provided direction in the school selection for this ethnography.

This study looked at the relationship of one school with external providers who were engaged to support the school's PE programme. This school is not intended to be representative of the educational system but does share the characteristics of many primary schools in Ireland which have limited indoor space for PE and only a small space for play outside. A lack of facilities impacted the structure of PE within this school as it does many other schools in Ireland.

The ethical approval to conduct the study was received from the University of Limerick.

\section{Context}

The school selected for study is a small, mixed-gender school, with 12 school staff and fewer than 200 students. The school is classified as a DEIS school. It has no indoor space for PE, and only a 
small yard for outdoor activities. One day per week the school used the pitch and the community centre building of the local sport organisation, the Gaelic Athletic Association (GAA), $5 \mathrm{~km}$ away, for PE. During the school year, students in all class grades experienced a block of swimming lessons, and a block of coaching sessions with external GAA coaches. In addition to these two coaching blocks, the primary class teacher or another adult/coach/instructor provided PE lessons on other weeks of the year. Fourth, fifth and sixth classes (ages 8-11) were selected as a focus for this study because they were experiencing PA external provision at the time of the study. The three classes selected experienced an eight-week block of PA external provision from May to June 2018. The structure of these eight weeks was quite complex. One external provider offered Frisbee sessions, a second provided fitness sessions and a third provided Gaelic football sessions across all three grades. The external providers delivered the Frisbee and Gaelic football sessions at the community centre, with fitness sessions delivered at a private gym located $8 \mathrm{~km}$ from the school. During these eight weeks, other external providers were also involved with the school. For the first four weeks, one parent trained the athletics team during PE class time. Each week the three grades rotated the external provision, so that if doing Frisbee the first week, they did Gaelic football the following week, and fitness class during the third week. The process of classes rotating (see Table 1) between the three activities gave the opportunity for students involved in the athletic team to experience the three other activities at least once. During the GAA sessions, one class had the opportunity to experience rounders. This session was more of a demonstration of the sport for teachers and how they might teach rounders in their classes when the coaches had left the school. All the sessions were $1 \mathrm{~h}$ long each week with students out of the school for $2 \mathrm{~h}$ travelling to and from the local facilities. These externally provided sessions were the only PE experienced by students during this eight-week block.

\section{Participants}

Participants involved in the study were two generalist teachers, one PE coordinator and three external PA providers. The two generalist teachers were selected because their classes were involved in the process of PA external provision. All the participants and companies are identified with pseudonyms.

Sophie and Danny were the two teachers involved in the study. Despite their different inclinations toward sport, they both stated they enjoy teaching PE. Nora was the PE coordinator of the school. Usually, this role is covered by someone with some longevity in the school. The role of the PE coordinator was to manage, timetable and organise PE classes, including the selection of external people to invite into the school setting. Hence, the PE coordinator is the person in charge of PE in the school. In this specific case, Nora's class was receiving external provision, hence she acted as both a class teacher and PE coordinator.

Table I. Eight weeks external provision structure.

\begin{tabular}{lcccccccc}
\hline & Week I & Week 2 & Week 3 & Week 4 & Week 5 & Week 6 & Week 7 & Week 8 \\
\hline Class I (level 4) & Fitness & Frisbee & GAA & Fitness & Frisbee & GAA & Fitness & Frisbee \\
Class 2 (level 5) & Frisbee & GAA & Fitness & Frisbee & GAA & Fitness & Frisbee & GAA \\
Class 3 (level 6) & GAA & Fitness & Frisbee & Rounders & Fitness & Frisbee & GAA & Fitness \\
School team & Athletics & Athletics & Athletics & Athletics & & & & \\
\hline
\end{tabular}


While all three external providers agreed to be involved in the project and be observed during the sessions with students, only Wayne, who provided Frisbee sessions, accepted our invitation to be interviewed about his role in the school. Wayne had no coaching qualification at the time of the study, but he was planning to attend a course the following summer. Caoimhe was the instructor providing the fitness sessions and had experience working with secondary school students, but this was her first experience working with primary students. In her gym, she was providing fitness classes for children of different ages. Tom, the GAA coach, was in his fourth year working with the school and was engaged in a similar capacity with other schools. See Table 2 for details about the participants and what data were collected from whom.

\section{Data collection}

The two main data sources for the project were individual semi-structured interviews and field notes collected during observations of PA and sport external provision. A third data source consisted of notes from informal conversations with each of the stakeholders (external providers, teachers and PE coordinator) and the lead author's reflections from these conversations and field notes during school observations. In addition, a research diary was created, and it was used to collect reflections and thoughts during the data collection and data analysis steps. Four individual semi-structured interviews were conducted; one each with Sophie and Danny, whose students experienced the PA external provision, one with Nora, the school PE coordinator, and one with Wayne, the external provider. During the interviews, questions focused on teacher involvement with external provision for PE; for example, How did you end up being involved in this process? and How did the external provider end up working with your students? Similar questions were asked of the external provider, including: How did you end up being involved in this process? Did you contact the school? All interviews were recorded and transcribed.

Field notes were used to document all observations of PA external provision. Particular attention was paid to the teaching method(s) used by the external provider in working with the students, the role of the actors (teachers and external providers) involved in these experiences and the content of

Table 2. Participants' characteristics.

\begin{tabular}{|c|c|c|c|c|}
\hline Name & Role & $\begin{array}{l}\text { Years of experience in the } \\
\text { school setting }\end{array}$ & Qualification & Data collection \\
\hline Sophie & Teacher & 9 years & Teacher & $\begin{array}{l}\text { Interview, observations, } \\
\text { informal talks }\end{array}$ \\
\hline Danny & Teacher & 2 years & Teacher & $\begin{array}{l}\text { Interview, observations, } \\
\text { informal talks }\end{array}$ \\
\hline Nora & $\begin{array}{l}\text { PE } \\
\text { coordinator }\end{array}$ & II years & Teacher & $\begin{array}{l}\text { Interview, observations, } \\
\text { informal talks }\end{array}$ \\
\hline Wayne & $\begin{array}{l}\text { External } \\
\text { provider }\end{array}$ & 2 years & None & $\begin{array}{l}\text { Interview, observations, } \\
\text { informal talks }\end{array}$ \\
\hline Caoimhe & $\begin{array}{l}\text { External } \\
\text { provider }\end{array}$ & $\begin{array}{l}\text { Ist time working for } \\
\text { primary school }\end{array}$ & $\begin{array}{l}\text { Fitness coaching } \\
\text { qualification }\end{array}$ & $\begin{array}{l}\text { Observations, informal } \\
\text { talks }\end{array}$ \\
\hline Tom & $\begin{array}{l}\text { External } \\
\text { provider }\end{array}$ & 4 years & None & $\begin{array}{l}\text { Observations, informal } \\
\text { talks }\end{array}$ \\
\hline
\end{tabular}


the sessions. In total, the lead author spent $20 \mathrm{~h}$ in the school setting, one day per week across five weeks.

Informal conversations occurred with all stakeholders at various times throughout the days of observations. Any information from these conversations that was related to the study was recorded immediately upon leaving the school.

\section{Data analysis}

The first author coded the interview transcriptions and field notes using both deductive and inductive data analysis. Deductive data analysis used pre-established categories, such as initiators and actors, gleaned from relevant literature and the theoretical underpinnings (Hastie and Glotova, 2012). Subsequently, inductive data analysis generated themes that contributed further understanding of the data set. This process involved reading and re-reading the interview transcripts and field notes to become familiar with the data. Open and axial coding strategies were used with the transcripts. The open coding allowed the identification of specific pieces of the transcription and field notes aligned to the research questions and aim of the study (Glaser, 2016). Successively, codes identified during this first step were connected to categories through axial coding. Axial coding allowed for the merging of data elements in new ways (Corbin and Strauss, 1990). For example, original codes included goal of PE and communication and these were then merged into the theme titled 'dynamics of the network'.

Trustworthiness was established utilising several techniques. A research diary was created and maintained during the full project. Information regarding data collection, the theoretical framework, methodological decisions and personal reflections were noted in the diary. Triangulation was obtained in two ways: interviewing people who represented three different positions (i.e. PE coordinator, teachers and external provider) in the network of provision and using multiple data sources (i.e. field notes, interviews and observations). The second and third authors served as peer debriefers to question and clarify the lead author's thoughts and by reading all data analysis documents and drafts of the papers, probing and clarifying findings, interpretations and conclusions.

\section{Results}

Two themes were constructed to represent the infrastructure of external provision in this primary school: 'a tangled web' and 'dynamics of the network'.

\section{A tangled web}

A tangled web represents the complex and multi-faceted nature of the people and the roles they played within the confines of PE external provision in this primary school. Three main categories of people represented the actors involved in the network: school staff, external providers and 'influencers'. These groups, while working with the same children, most often acted independently, not knowing or communicating with each other. Further, they came from different supporting agencies, with different expectations and goals for children, resulting in a misalignment between what was expected and what happened during the provision. It is important to highlight that the actors reported in this analysis were people or agencies mentioned by the participants. 
School staff. School staff were those people who were working in the school and employed by the school. They were all qualified teachers; the school, its policies and curriculum, and the children, provided their collective common ground. This group included teachers and the PE coordinator with each playing different roles. At the forefront was Nora, the PE coordinator. The field notes collected indicate that she was:

In charge of managing the PE external provision. She indicated which class was going for the provision, and also during the first day of provision, she talked with the fitness external provider in regard to the age group of the class. (3/05/2018)

Sophie, a teacher in the school, later confirmed that in this instance, "Nora is the PE coordinator of the school at the moment, and she is in charge of PE'. Hence, Nora would also be responsible, in theory, for all external provision.

Within the provision teachers' roles varied. Some teachers became class managers, not directly engaging with the content of the lesson. For example, in Sophie's class during the time of external provision she sat on the side of the activity space and was focussed on managing student behaviour and checking that children were not going off task [field notes, 3/05/2018]. She only interacted with children when misbehaviour was apparent. In contrast, other teachers assumed more active roles in the lesson and assisted the external provider. Danny provided evidence of this as he was observed assisting the GAA external provider by refereeing [field notes, 17/05/2018]. For these teachers the role they assumed during provision seemed to be one that was self-identified, not defined by the school or the provider.

One of the school staff jobs was also to initiate the contact with external providers. Sophie affirmed that, 'We [the school] would have contacted the Frisbee people, and 'the Body Line' [the gym] and I think Nora has a contact for rounders as well'. Nora also reported that an invitation was forwarded from the school to two parents, one to train students who had qualified for the county athletics final competition and another to train the school soccer team for a county blitz. Swimming lessons were also arranged in the community by the schools. The process of inviting external people was confirmed by the external provider Wayne, 'they [the school] contacted me or our university [team]'. The same happened to fitness instructor Caoimhe, who was sourced a few days before the beginning of the eight-week teaching block to deliver fitness class [informal conversation, 3/05/2018].

External providers. The second group working in the school were those providing external provision. This group included a variety of people such as employees of National Governing Bodies (NGBs), local sports coaches, parents, regional developmental officers and athletes. The most predominant NGB represented in the school was the GAA - providing sessions of hurling, camogie, Gaelic football and rounders. Representatives of this NGB differed in their levels of skills and knowledge. The members of the GAA group included sports coaches, athletes and developmental officers, each with different levels of experience and expertise in relation to the content they were providing at the school. As suggested by the PE coordinator, 'The GAA would be involved, and they would be providing us with a hurling and camogie coach' (Nora). The GAA offered rounders once during the eight-week block to one class. Basketball, through Basketball Ireland, was sourced externally but did not happen during the period of data collection. In addition, Sophie highlighted that, 'One of the parents comes in to teach soccer.' Later, Nora reported another parent was involved in training the athletics team. 
While one of the roles of the school staff was to contact external providers to request their services, external providers also contacted the school to offer their services. Specifically, Nora recounted that, 'the GAA coaches contact the school... [and] rugby also contacted us'. Curiously when provision was initiated by the external providers, the service was usually free of charge; in contrast, when the school was the initiator of the relationship with sport associations and NGBs, the provision of the service was paid by the school. In total for the academic year, five out of eight provisions came about as a result of a school invitation to work with the students and two of those five were free volunteer services of two parents. The other three provisions were a result of a request from external providers to offer a service for the school. Hence, at times, the school was the initiator of the invitation to a number of external providers and at other times the external providers sought permission to offer a service to the school. There were no guidelines or consistency in terms of how to initiate or decide on a network/relationship between the school and PE external providers. As Nora summarised, 'There is no given, sometimes we contact them and then sometimes they contact us'. Inconsistency seems to be the given and not seen by staff as problematic.

Influencers. The third group in this tangled web of provision we termed 'behind the scenes' actors. These people were unrelated to the school and were not providing any external provision to the school, but influenced the nature and scope of external provision. This group of influencers included teachers and school staff from other schools, as well as professional association members involved in the enactment of services for schools and teachers (i.e. Professional Development Service for Teachers (PDST)). Nothing tied this group together; they were simply people who wanted to support student engagement with PE and their roles varied greatly. These 'behind the scenes' actors both directly and indirectly influenced the establishment of the network. The direct influencers did not deliver the service themselves, but actively sought to 'match-make' by putting the external provider and the school in touch with each other. Nora explained the role played by another school as a direct influencer:

We had heard of what another school enjoyed, and we hadn't done [that] so that's why we went with that one [badminton]. And again, the gym [instructor] was something that we heard [about] and our [local] secondary school was accessing [them] so we thought that might be interesting as well.

Another example of a direct influencer was a governmental agency providing professional development services to facilitate capacity development of teachers' knowledge of curriculum content and pedagogical approaches in PE. As explained by Nora:

There is, what it is called, a teacher professional community (TPC) ..., it's run through the College of Education Centre and by a group called the PDST, so they have evening meetings and after-school courses for teachers... So, for example, they chose basketball one evening. I did the course, I thought the basketball coach there was excellent, so we contacted him and he provided our coaching lessons, same thing with badminton.

These indirect influencers were involved in some sort of collaboration with one of the stakeholders. A clear example of this is the relationship between the external provider and his coach in gaining information as to what he should do when working in school with children. Wayne 
explained: 'I went to my own coach and asked for tips...just talking with people and see what works and doesn 't'. Hence, the coach acted as an advisor for the external provider who probably was seeing the coach as a mentor.

The actors and their roles in the tangled web depict intertwined and overlapping responsibilities. These intertwined and overlapping responsibilities reflect the lack of clarity regarding "who is doing what' concerning the roles played by the actors in the sourcing and provision of external PA sessions for students. While the results clearly indicate the nature of the roles played by some actors, there was some confusion as to the roles of other actors. At a fundamental level the role of the PE coordinator was contested. While the role of PE coordinator around external provision was quite clearly understood by her, 'I would be coordinating with the outside agencies and setting up [some] sort of rotas/timetables and arrangements so that the children in our school get as much interaction with sports as they can' (Nora), Danny, as a teacher, indicated that, 'I'd be involved and getting external people in to do some sort of PE session'. Similarly, it was not always possible to identify one person from the sport associations, who connected with the school. In some agencies (e.g. GAA), there was a specific person in charge of making contact with schools (e.g. sport development officer) and arranging for the coach to visit the school; yet, for other agencies the coach did everything from contacting the school, to developing lesson plans, to determining a timetable.

Collectively, the exploration of the enactment of PE external provision illuminates the myriad of roles played by teachers and external providers during the provision. These roles varied from teacher to supervisor, behaviour manager, supporter or onlooker and these roles varied between and within class groups. For example, Wayne, acting as a teacher, had a lesson plan, developed in collaboration with his coach and before starting the lesson he set up all the equipment needed [field notes, 10/05/2018].

The school would not have any past experience with Frisbee, so they leave it all up to us. All we ask of the school is that the teacher will get involved and if the teacher is nearby just if there is kind of management, but in terms of lesson plans it's up to me. (Wayne)

Nora and Danny, in a supervisory capacity, went on the bus with students to the GAA community centre, but were not engaged with the content of the session at the centre. Similarly, the selection of the classes involved in the external provision was sometimes influenced by the external provider rather than the teacher. Sophie indicated that, 'The hurling coach has said to us that it's better to teach younger children to get the skills in earlier, so the hurling coach prefers to work with the junior students'. Later she added, 'we had a rugby coach and he wanted to work with first and second classes'. On these occasions, the external provider decided the age group of students they would work with in the school based on what they believed best aligned with their developmental levels to develop the skill required in that specific sport. The opposite situation also occurred with the PE coordinator and teachers deciding which class to work with the external provider. Hence, coaches working in this school were in charge of planning and delivering the content of the lesson, a role that usually belongs to teachers, who, instead, had a secondary role managing student behaviour. It was quite clear that different actors (in this case external providers) adopted different roles in engaging with the students during these sessions.

This tangled web represented over 10 actors who crossed paths during the school day, but rarely interacted with each other. They all knew someone in the web, but no one knew everyone. Sometimes the role covered was clear, at other times responsibilities were uncertain. In other words, this tangled web reflected the confusion, the complexity and messiness of the network. 


\section{Dynamics of the network}

Dynamics of the network is the second theme and refers to the infrastructure of the external provision and the subsequent impact on PE in this primary school. It represents the understandings between the school personnel and the external providers. Two subthemes describe these dynamics, 'A Communication System' and 'A Shared Purpose'.

A communication system. A tacit communication system between the school and two of the external providers (GAA and swimming) was firmly in place. The school and these external providers had worked together for many years. In that time, they developed an unspoken relationship of what to expect of each other. Communication to and from the school to the providers made no mention of instructional content or goals for the programme or how their work might align with the PE programme. Rather the focus was on minor organisational matters. As Sophie explained:

Ever since I've been here, we've had hurling and football coaches. I think it's kind of a system that's kind of in place, where the GAA coaches contact the schools and say you know, 'would you like a coach?', and obviously we say 'yes, please.'

Nora reported similarly about the relationship between the school and the local swimming pool:

We have the same slot [swimming] every year, we just confirm it because our numbers are different each year, so we confirm numbers because depending on our numbers, that depends how many teachers [swimming instructors] they have to have available to us when we go down there.

The communication dynamic between the school and the external providers reflected two different routines depending on the initiator of the provision. In the first type of communication, the school requested the service. In this instance it was swimming lessons for students from the staff at the local swimming pool. The second type of communication was a request from an external provider to the school principal to provide a service at the school. One example of this second type of request was the local GAA offering to provide coaches to the school. Despite the implicit nature of both routines, they represented fundamentally different underpinnings. Swimming was a required part of the curriculum and 'needed' to be taught, and as the school had no swimming pool, they sought to engage with the local facility and its staff to assist them attend to that element of the curriculum. In the case of the GAA provision, there was a perception that the local GAA club had the interest, knowledge and resources to provide a better learning experience for students for this aspect of the games strand of the curriculum. The negligible topics of the communication in both relationships confirm however that the system was in place and as a consequence there was no need to have robust conversations with the external providers.

A shared purpose. The second subtheme reflects the dynamic of the stakeholders' purpose for PE in primary schools. In contrast to the tacit communication dynamic, in this case the external providers and the school explicitly shared a purpose regarding PE in primary schools. For all the actors, getting students active was seen as the main goal of primary PE and one of the main reasons to justify the presence of external providers in the enactment of the PE curriculum. In support of this, Danny, a teacher, explained the reasoning for external provision as, "to get the kids physically active, at least they are getting the one hour'. This perspective of the purpose 
of PE relating to PA was also shared by Wayne, an external provider, who stated that, '[the aim of $P E$ in primary schools] is to get kids out active and fresh air in the lungs'. This attitude was further reflected in the content provided during the provision. All the PA external provision observed was aimed to develop foundational movements of the sport played that day; field notes indicated that 'it looks like children are in a training session of Gaelic Football' [24/05/ 2018]. Other goals of PE were however mentioned by the stakeholders. For example, the teacher Sophie and the external provider Wayne both mentioned the opportunity for 'students to have fun' while Danny suggested that 'in the lower end [the goal of PE] to be about fine and gross motor skills'. The point on which all stakeholders seemed to agree was in seeing the promotion of physically active lifestyles as the main goal of PE. This was supplemented by the idea of providing fun activities and developing foundational motor skills. This perception however reflects a narrow view of PE. In fact, none of the other aims of PE, such as the promotion of social and emotional development of the child or developing positive personal qualities were mentioned by stakeholders.

\section{Discussion and conclusion}

The purpose of this study was to understand the external provision infrastructure supporting PE in an Irish primary school. Specifically, we sought to understand how the external provision infrastructure supported PE work and the key features and impact of external provision on school PE. de Lima's (2010) concepts of network dimensions were used to analyse the network between the school and several external providers they engaged to work with their students and staff. In this circumstance, the genesis and effectiveness dimensions are the most relevant; however, when discussing this last dimension, composition and substance were mentioned.

\section{Genesis dimension: The initiator}

The initiator concept, in this case who invited whom to work with students during the school day, represents the genesis dimension and indicates network ownership (de Lima, 2010). The current situation presents an interesting exemplar of that concept. In this study, the initiator concept would mean that when the school contacted the external provider, the school was the owner of the network and was in charge of deciding the content to be delivered. Alternatively, when the external provider initiated the relationship, they decided what to deliver and the goal of the delivery. The current findings however do not align with de Lima's genesis assumption as when the school was the owner/initiator of the network they always delegated the decision on what type of experience to deliver to the external provider. Their reasons for doing this align with the findings of Powell (2015) and Williams and Macdonald (2015) who reported that the school staff viewed the external providers as experts and better positioned to make relevant content decisions. If a decision of content offered to schools in these sessions is an indication of ownership, the school never owned the network or asserted control over the elements of content in these 'lessons'. The external providers made all these decisions, demonstrating the power imbalance (de Lima, 2010) between members of the network and the lack of autonomy of the school. The school, in many cases, was losing autonomy in taking decisions such as classes to involve, activities to deliver and learning outcomes to promote. Furthermore, the division of labour in the school 
between school staff and external providers was far from the equal division described by Williams and Macdonald (2015). It is interesting that despite the Irish Primary Physical Education curriculum (1999a: 28) specifying that, 'the teacher must retain overall responsibility for planning, control and monitoring to ensure that the child's physical activity is coherent, consistent, progressive and controlled', the roles described of these actors (e.g. parents and sport coaches) were far different. Aligned with Lavin et al. (2008), who identified teachers' perceptions of poor behaviour management skills demonstrated by coaches, the teachers' role in the present study was essentially managerial while the external provider took charge of planning and delivering the PE content. However, the curriculum documents stated teachers should be in charge of planning and assessment of the PE programme not the external providers (Government of Ireland, 1999a, 1999b). External providers are described as supporters for the PE programme and all aspects of their contributions should be decided and agreed on by the class teacher, who should ensure the contributions of the external providers meet curriculum requirements and needs of the pupils (Government of Ireland, 1999a, 1999b).

\section{The effectiveness dimension}

The relationship of the school with external providers was quite complex because of the variety of people to be managed who were coming into the school to provide a service and the myriad of levels of expertise and agendas for their engagement with the school. This ultimately impacted the effectiveness of the network. As suggested by the European Commission (2018), the effectiveness dimension can be determined by the analysis of three elements (goals, process and structure) of the partnership between the school and the providers.

Regardless of the affiliation and background of stakeholders, the shared goal was the promotion of PA and getting students more physically active. If the presence of a shared goal between actors allows for the classification of this infrastructure as a network, then the nature of the shared goal reflects a narrow view of the aim of PE in primary schools, which was focused only on the physical component of the subject, leaving behind all the social, cognitive and affective aspects (Government of Ireland, 1999a). Furthermore, the networks disregarded an explicit focus on student learning in these sessions with little evidence of awareness or alignment with the Irish Primary Curriculum (Government of Ireland, 1999a). It was not clear how the NGBs' focus on sport aligned with the goals of the Irish Primary PE curriculum that they believed they were supporting, through the PA external provision. These external provision sessions often were substituted for the instructionally allocated PE time. Furthermore, the shared goal was not explicitly discussed when establishing the relationship.

The process aspects or how things were going to happen was based solely on the communication of managerial aspects such as the number of students attending and the structure of the external provision rather than any learning outcomes, pedagogical or curricular discussions. Ní Chróinín and O'Brien (2019) highlighted that the core of an effective relationship requires shared planning to achieve the curricular learning outcomes. As a consequence, the effectiveness of the network was seriously compromised by the lack of communication between the stakeholders on key learning outcomes.

The structure element of the European Framework refers to how the connections were made. In this mixed-level network (de Lima, 2010) where individuals and groups worked simultaneously, each relationship presented a unique situation. Some were direct connections between the main actors of the network and others were more complex where the help of other people was required; 
some were initiated by the school and others by the external providers; some were one-time relationships; others were annual relationships. Specifically, the externally initiated long-established relationships anticipated the expectations of both sides, with the school expecting to be contacted by the external provider and the external providers knowing that the school will accept their invitation to work with their pupils. In line with what is described by Williams and Macdonald (2015: 67) as 'a joint elaboration between consumers and producers', the relationship between external providers and schools is much more complex than perceived and both parts benefit from participation in the network. Furthermore, the relationship in the network is not only between the actors, but following the definition offered by Ball et al. (2017), there are other elements that exacerbate the complexity of the network. In our scenario, the network involves a set of facilities including the swimming pool, the local gym and the GAA pitch, and the Irish Primary PE curriculum. In fact, the network is created to support and achieve the goals of PE described in the Irish Primary PE curriculum. Consequently, we could consider this last document also as part of the network.

Therefore, it can be concluded that despite the presence of all three elements of the European Framework, the dynamics of the network as presented above compromised its efficiency. Loss of autonomy and a power imbalance between the main actors emerged as the two dark side elements of the network.

\section{Neoliberalism in this school}

The pervasiveness of neoliberalism in society lies in opportunities to choose the 'best' options available (Evans, 2014). This scenario of selecting the best option has become common, not only between individuals, but is also visible in the public domain, including education. As claimed by Evans (2014), PE is not exempt from this neoliberalism trend, and in this study plays out in the decisions of the school leadership to engage external providers to support the PE programme. Hence, the school developed relationships with various associations and individuals, and the existence of these external providers was considered to be normal practice as is the case in school networks globally (Petrie et al., 2014). This however was not the only impact of neoliberalism on PE in this school. The dynamics of the network and the relationships between the actors, specifically between the teachers and external providers, resulted in a swapping of power in their interactions with students (Powell, 2015). Power in this case was reflected in the perceived expertise of the external providers. This expertise, however, was equated solely to sport knowledge (Powell, 2015), often void of pedagogical background (Dyson et al., 2016; Powell, 2015), hence, the expertise of the external provider was perceived as more relevant than their knowledge (Enright et al., 2020). The perceived expertise was compounded by teachers whereby many abdicated their instructional roles. This power reversal calls into question expertise in the education process and thus seems to affirm that the network is not fully supportive of the learning outcomes of PE as intended in the Irish educational system and to all those school curriculums that have a holistic purpose of PE.

In conclusion, the external provision process in this school changed the roles of the stakeholders, to the point where the teachers were not in charge of significant elements of the selection and/or enactment of the PE curriculum. Instead, this evolution of how the teachers operate within this network suggests they act more as facilitators and supporters for the external providers than educational leaders of their students' education in PE. The external providers in this school decided the PE content and the pedagogical approaches to working with the pupils. In other 
words, external providers in this school were reshaping PE content, transforming it from PE into a focus almost exclusively on PA. External providers made all decisions about the content to be taught, the planning of the lessons and the teaching of the content. In covering all these roles and making all these decisions, external providers became de facto owners of these elements of the PE curriculum, with any decisions left to the school more likely to be managerial rather than instructional. The question remains - are these the best curricular options for children and the study does provide insights into the benefits and drawbacks for students and staff when choosing to engage in such practices. While this study represents the Irish context it does provide an example of how the relationship between a school and external providers works. This study reflects the complexity of the outsourcing system and how the mere presence of the elements of an effective network (European Commission, 2018) does not make the system efficient or necessarily effective. Understanding these complexities could provide a starting point for understanding outsourcing in other contexts as well as providing a more informed point of departure for transforming the Irish system.

\section{Declaration of conflicting interests}

The authors declared no potential conflicts of interest with respect to the research, authorship, and/or publication of this article.

\section{Funding}

The authors received no financial support for the research, authorship and/or publication of this article.

\section{ORCID iDs}

Jessica Mangione (D) https://orcid.org/0000-0002-5448-2485

Melissa Parker (D) https://orcid.org/0000-0002-0257-5516

\section{Notes}

1. While we are well aware of the distinctions made in the literature between physical education and physical activity, in this article, these two terms are intentionally used interchangeably as it reflects teachers' and schools' references to their experiences in the study setting.

2. DEIS is an action plan developed by the Irish Department of Education and Skills. The plan aimed to address educational disadvantage. DEIS schools are provided with additional resources and staff to support the additional needs of many of the students attending these schools.

\section{References}

Ball SJ (2004) Education for Sale! The commodification of everything? Available at: http://www.asu.edu/educ/ epsl/CERU/articles/CERU-0410-253-OWI.pdf (accessed August 2020).

Ball SJ (2012) Global Education Inc.: New Policy Networks and The Neoliberal Imaginary. London, England: Routledge.

Ball SJ, Junemann C and Santor D (2017) Edu. net: Globalisation and Education Policy Mobility. London, England: Routledge.

Barringer BR and Harrison JS (2000) Walking a tightrope: Creating value through interorganizational relationships. Journal of Management 26(3): 367-403.

Bowles R and O'Sullivan M (2012) Rhetoric and reality: The role of the teacher in shaping a school sport programme. Physical Education and Sport Pedagogy 17(3): 303-316. 
Corbin J and Strauss A (1990) Grounded theory research: Procedures, canons, and evaluative criteria. Qualitative Sociology 13(1): 3-21.

de Lima JA (2010) Thinking more deeply about networks in education. Journal of Educational Change 11(1): 1-21.

Department of Education and Skills (2018) Best practice guidance for port primary schools in the use of programmes and/or external facilitators in promoting wellbeing consistent with the Department of Education and Skills' Wellbeing Policy Statement and Framework for Practice. Available at https://assets.gov.ie/ 12379/01ceb058399447b0922827c70064986b.pdf (accessed September 2018).

Dyson B, Gordon B, Cowan J, et al. (2016) External providers and their impact on primary physical education in Aotearoa/New Zealand. Asia-Pacific Journal of Health. Sport and Physical Education 7(1): 3-19.

Enright E, Kirk D and Macdonald D (2020) Expertise, neoliberal governmentality and the outsourcing of health and physical education. Discourses: Studies in the Cultural Politics of Education 41(2): 206-222.

European Commission (2018) Network for Learning and Development Across School Education. Guiding Principles for Policy Development on the use of Networks in School Education System. Brussels: European Commission. Available at: https://www.schooleducationgateway.eu/downloads/Governance/ 2018-wgs5-networks-learning_en.pdf (accessed May 2020).

Evans J (2014) Neoliberalism and the future for a socio-educative physical education. Physical Education and Sport Pedagogy 19(5): 545-558.

Evans J and Davies B (2014) Physical education PLC: neoliberalism, curriculum and governance. New directions for PESP research, Sport, Education and Society 19(7): 869-884. DOI: 10.1080/13573322.2013. 850072.

Evans J and Davies B (2015) Neoliberal freedoms, privatisation and the future of physical education. Sport, Education and Society 20(1): 10-26.

Glaser BG (2016) Open coding descriptions. The Grounded Theory Review 15:2. Available at: http:// groundedtheoryreview.com/2016/12/19/open-coding-descriptions/ (accessed December 2019).

Government of Ireland (1999a) Primary School Curriculum. Dublin: The Stationary Office.

Government of Ireland (1999b) Primary School Teacher Guidelines. Dublin: The Stationary Office.

Hadfield M, Jopling M, Noden C, et al. (2006) What Does the Existing Knowledge Base Tell us About the Impact of Networking and Collaboration? A Review of Network-Based Innovations in Education in the UK. Nottingham, UK: National College for School Leadership.

Hastie PA and Glotova ON (2012) Analyzing qualitative data. In: Armour K and Macdonald D (eds) Research Methods in Physical Education and Youth Sport. London: Routledge, pp.309-320.

Howard PN (2002) Network ethnography and the hypermedia organization: New media, new organizations, new methods. New Media \& Society 4(4): 550-574.

Irish Primary Physical Education Association (2010) The Role of the External Provider in primary School Physical Education. Available at https://www.irishprimarype.com/wp-content/uploads/2014/12/ RoleExternalProvider_Jan2011.pdf (accessed September 2018).

Lair CD (2012) Outsourcing and the contracting of responsibility. Sociological Inquiry 82(4): 557-577.

Larner W (2003) Neoliberalism? Environment and Planning D: Society and Space 21: 509-512.

Lavin J, Swindlehurst G and Foster V (2008) The use of coaches, adults supporting learning and teaching assistants in the teaching of physical education in the primary school. Primary Physical Education Matters 3(1): 9-11.

Macdonald D (2011) Like a fish in water: Physical education policy and practice in the era of neoliberal globalization. Quest 63: 36-45.

Macdonald D (2014) Is global neo-liberalism shaping the future of physical education? Physical Education and Sport Pedagogy 19(5): 494-499.

Mangione J, Parker M, O', et al. (2020) Mapping the landscape of physical education external provision in Irish primary schools. Irish Educational Studies 39(4): 475-494.

Ní Chróinín D (2017) Primary physical education in the Republic of Ireland/Éire. In: Griggs G and Petrie K (eds) Routledge Handbook of Primary Physical Education. London: Routledge, pp.205-216. 
Ní Chróinín D and O’Brien N (2019) Primary school teachers' experiences of external providers in Ireland: Learning lessons from physical education. Irish Educational Studies 38(3): 327-341.

Nohria N (1992) Is a network perspective a useful way of studying organizations? In: Nohria N and Eccles RG (eds) Networks and Organizations: Structures, Form, and Action. Boston, MA: Harvard Business School Press, pp.1-22.

Parnell D, Buxton S, Hewitt D, et al. (2016a) The pursuit of lifelong participation: The role of professional football clubs in delivery of physical education and school sport in England. Soccer \& Society 17(2): $225-241$.

Parnell D, Cope E, Bailey R, et al. (2016b) Sport policy and English primary physical education: The role of professional football clubs in outsourcing. Sport in Society 20(2): 292-302.

Petrie K, Penney D and Fellows S (2014) Health and physical education in Aotearoa New Zealand: An open market and open doors?. Asia-Pacific Journal of Health, Sport and Physical Education 5(1): 19-38.

Powell D (2015) Assembling the privatisation of physical education and the 'inexpert' teacher. Sport, Education and Society 20(1): 73-88.

Sayama H, Cramer C, Porter MA, et al. (2016) What are essential concepts about networks? Journal of Complex Networks 4(3): 457-474.

Sperka L and Enright E (2017a) The outsourcing of health and physical education. European physical education review. European Physical Education Review 24(3): 349-371.

Sperka L and Enright E (2017b) Network ethnography applied: Understanding the evolving health and physical education knowledge landscape. Sport, Education and Society 24(2): 168-181.

Williams BJ and Macdonald D (2015) Explaining outsourcing in health, sport and physical education. Sport, Education and Society 20(1): 57-72.

\section{Author biographies}

Jessica Mangione is a lecturer in physical education and school sport at Edge Hill University (UK). At the time when the study was carried out, she was a $\mathrm{PhD}$ student at the University of Limerick (Ireland). Her main research interests are physical education external provision, models-based practice and student voice.

Melissa Parker is a senior lecturer emerita in physical education and sport sciences at the University of Limerick. Her research interests include teacher and teacher educator professional development and student and teacher voice.

Mary O'Sullivan is a professor emerita at the University of Limerick. Currently, she chairs the Irish National Council for Curriculum and Assessment. She is interested in educational policy change. 